\title{
UMA ABORDAGEM PARA POSICIONAMENTO E DIMENSIONAMENTO DE ESTOQUES DE COUROS AFTERMARKET NA CADEIA DE SUPRIMENTOS
}

\author{
A proposal of approach to positioning and sizing of \\ inventory leather to aftermarket supply chain
}

\section{Daniel Pacheco Lacerda ${ }^{1}$ Secundino Luis Henrique Corcini Neto ${ }^{2}$}

\section{Resumo}

A prática atual de gerenciamento de cadeias de abastecimento tende a forçar o encaminhamento de produtos para o varejo na cadeia de suprimentos. Esta atitude, por consequência, mantém os estoques o mais próximo possível do consumidor, contabilizando, para os fornecedores, vendas realizadas. Valendose dos princípios da Teoria das Restrições (TOC), para o gerenciamento de sistemas de distribuição, buscou-se definir o posicionamento e o local para manter os estoques, a fim de atender o mercado nacional de couros automotivos, denominado aftermarket. Este artigo, portanto, sugere a criação de estratégias e ações que possibilitem ofertar ao cliente os produtos desejados, na quantidade, no local e no tempo certo, evitando a falta do produto no ponto-de-venda.

Palavras-chave: Teoria das Restrições; Localização de Estoques; Indústria de Couro Aftermarket; Distribuição Puxada.

\footnotetext{
${ }^{1}$ Doutorando em Engenharia de Produção, Universidade Federal do Rio de Janeiro (COPPE/UFRJ); mestre em Administração, Universidade do Vale do Rio dos Sinos (UNISINOS), professor da Área de Administração da UNISINOS. E-mail: dlacerda@ufrj.br-dlacerda@unisinos.br

${ }^{2}$ Mestrando em Engenharia de Produção e Sistemas (Unisinos); especialista em Gestão Empresarial, URI/Santiago; professor universitário do curso de Administração URI/Santiago nas disciplinas de Administração da Produção e de Administração de Materiais. E-mail: secundino.corcini@hotmail.com.br
} 


\begin{abstract}
The current practice of supply chain management tends to force the forward of products to retail in supply chain. These attitudes maintain the inventory as near of consumer, accounting for suppliers sales. Using Theory of Constraints (TOC) principles to management of distribution systems, we attempted to define the place to maintain inventory to meet the domestic market for automotive leather called aftermarket. This paper, therefore, suggests the creation of strategies and actions that enable the customer offer the desired products, quantity, at the place and right time, avoiding the failure of the product at the point of sale.
\end{abstract}

Keywords: Theory of Constraints; Inventory Location; Leather Industry Aftermarket; Distribution Drawn.

\title{
1 Introdução
}

A queda no preço do couro, aliada a sua durabilidade, movimenta o mercado automotivo na direção da substituição dos estofamentos fornecidos, originalmente, em tecido para revestimentos em couro. Este mercado possui razoáveis possibilidades de expansão, porém apresenta particularidades em seu atendimento, tais como: velocidade de entrega e lotes pequenos. Tais particularidades são determinantes na condução das estratégias de produção nesse segmento do setor de couros.

A diversidade de artigos para estofamento mobília a partir do couro curtido wet blue é significativa. Este fator faz com que, normalmente, a gestão dos estoques dentro da empresa acabadora se situe ou no início do processo (onde ele pode ser direcionado para vários tipos de artigos) ou no cliente (empresa de corte-costura ou varejista). Quanto maior o avanço dentro do processamento, maior a personalização do artigo em termos de maciez, espessura, cor, brilho etc., dificultando seu redirecionamento para outro cliente.

Os conceitos de gestão dos estoques do estofamento mobília, não podem ser aplicados ao estofamento automotivo, pois apresenta baixa diversidade de características nos artigos e exige alta velocidade de entrega dentro do mercado nacional. Esta diferenciação é de suma importância para a definição da localização dos estoques dentro da organização acabadora, pois determina um fator de competitividade importante no atendimento ao mercado.

Para Kendall (2007), a medida da eficiência usualmente utilizada para a distribuição obedece aos mesmos mecanismos das operações, nos quais se mede o desempenho pela quantidade produzida, gerando um significativo volume de estoques. Menezes e Da Luz (2007) reforçam que a maioria dos estoques estacionam nos distribuidores e não nos produtores, porque este força o distribuidor que, por sua vez, pressiona o varejista a comprar mais.

Quem produz, vende com desconto para maiores quantidades, justificando perda de exclusividade se o distribuidor não comprar em grandes volumes, e isto se repete até o varejista. Dessa forma, toda a cadeia parece ser regida por um sistema de empurrar os produtos do produtor ao consumidor (SIKILERO, RODRIGUES e LACERDA, 2008).

Menezes e Da Luz (2007) fazem menção a dois tipos de distribuição que, genericamente, podem ser adotados, conforme a relação entre o índice de custo adicionado e a proximidade com o varejo: uma é a distribuição escalonada de produtos de baixo custo adicionado e 
com possibilidade de consolidação do transporte entre a indústria e o distribuidor; a outra é a distribuição direta a partir da indústria de produtos com alto custo adicionado, volumes elevados e proximidades com o varejista (SIKILERO, RODRIGUES e LACERDA, 2008).

A Teoria das Restrições (TOC) propõe uma metodologia para o gerenciamento da distribuição dentro da cadeia de suprimentos que focaliza o fornecimento em relação à demanda, fazendo com que os produtos sejam puxados ao longo da cadeia, do consumidor ao produtor. Menezes e Da Luz (2007) reforçam que, nessa metodologia, os estoques são menores nos pontos-de-venda com um centro de distribuição próximo à fábrica (agregar pedidos), frequência de reposição diária conforme as vendas do dia e emissão de ordens de produção também diárias para manter o nível de estoque do centro de distribuição (SIKILERO, RODRIGUES e LACERDA, 2008).

É nesse contexto da Teoria das Restrições que o presente artigo abordará o tema da distribuição. Nesse sentido, será apresentado um estudo de caso sobre a aplicação das técnicas da Teoria das Restrições na cadeia de distribuição. Cabe ressaltar que não se verifica trabalhos empíricos nesse sentido, sendo esta uma das contribuições centrais da presente pesquisa. A seguir será apresentado o referencial teórico. Em seguida, será evidenciado o método que conduziu os trabalhos e, por fim, os dados são analisados e as conclusões são tecidas.

\section{Referencial teórico}

A TOC (Theory of Constraints - Teoria das Restrições) adota por princípio a definição de que a meta da empresa é ganhar dinheiro hoje e no futuro (GOLDRATT, 1993; GUPTA e BOYD, 2008). Uma vez definida a meta, Goldratt (1993) orienta a identificação das restrições que impedem a empresa de alcançá-la. Desta forma, o desempenho geral da organização (sistema) é definido pelas restrições que o impedem de atingir seus objetivos (WATSON, BLACKSTONE e GARDINER, 2007; GUPTA e BOYD, 2008).

Tal raciocínio é extrapolado por Kendall (2007) na organização para uma cadeia de suprimentos específica, que alerta para o perigo da busca do ótimo local em detrimento do ótimo global por parte dos fabricantes, quando estes procurram empurrar seus estoques para toda a cadeia. Tal ação repercute nos distribuidores, que agem da mesma maneira em relação aos lojistas e, estes, aos seus clientes.

Esta ação aloca a maior parte do estoque na ponta da cadeia, ou seja, nos lojistas. Sob certo aspecto, pode-se argumentar que a variabilidade da demanda nos lojistas é superior em relação à do fabricante. Isso decorre do fato de que, nos fabricantes, as demandas estão agregadas (RAHMAN, 2002; SIKILERO, RODRIGUES e LACERDA, 2008). A Figura 1 procura ilustrar essa situação.

Esta ação, por consequência, força a existência de estoques ao longo da cadeia. Além disso, implica no posicionamento em quantidade significativa próximo do mercado consumidor, no qual a variabilidade da demanda por itens tende a ser mais significativa. Os modelos mentais voltados para a busca do ótimo local (fabricante) podem ser observados. Um exemplo disso ocorre quando fornecedores oferecem descontos por altos volumes para cada pedido individual e/ou penalizam o cliente que faz pedidos em pequenas quantidades. 


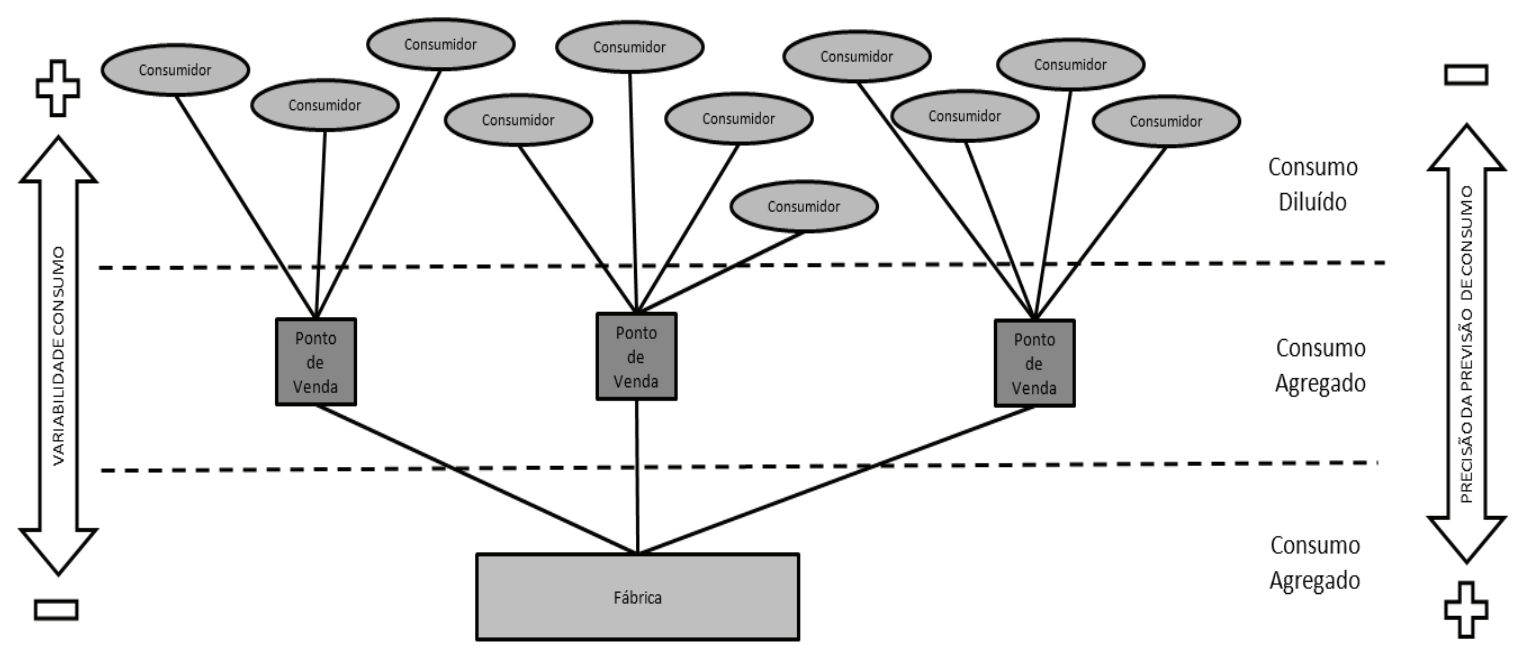

Fonte: adaptada de Goldratt e Goldratt (2008).

Figura 1 - Variabilidades ao longo da cadeia.

Goldratt e Goldratt (2008) e Kendall (2007) sugerem os três primeiros passos de focalização da TOC (GOLDRATT, 1991) para tratar da redução dos níveis globais de inventários dentro da cadeia:

a. Identificar a restrição do sistema: analisando os canais de distribuição, indagandose: "o que mais contribui para gerar ganho no canal?" A resposta é uma só: O CLIENTE, pois quanto mais clientes compram, maior é o ganho para o sistema (RAHMAN, 2002; KENDALL, 2007).

b. Explorar a restrição: Kendall (2007) vale-se de uma metáfora para elucidar este passo, afirmando que antes de gastar mais dinheiro para atrair um maior número de clientes, não desperdice aqueles que vêm até você. Ele se refere ao fato de que, por vezes, o cliente não compra devido à falta do produto no ponto-de-venda. Em algumas situações, o mesmo produto pode estar estocado em algum outro ponto da cadeia de suprimentos. Para isso, devese aumentar as chances de ter estoque certo, no tempo certo e no lugar certo para atender à necessidade do cliente (KENDALL, 2007; WATSON, BLACKSTONE e GARDINER, 2007).

c. Subordinar: Para Goldratte Goldratt (2008) e Kendall (2007), é necessário subordinar todo resto à decisão acima, de atender às expectativas de um cliente que vem comprar. Este é um dos desafios para se ter o produto certo, na hora certa e no lugar certo.

Por um lado, Kendall (2007) sugere que os estoques estejam concentrados nos locais onde há maior previsibilidade. Por outro lado, questiona sobre a lógica correta de distribuição dos estoques entre os fabricantes e os distribuidores e destes aos lojistas. Para Kendall (2007), deve-se implementar um sistema puxado para repor cada artigo individualmente, com base nas vendas em um curto espaço de tempo. Alinhando este raciocínio à realidade brasileira (condição das estradas, modais disponíveis, volume de tráfego nos grandes centros etc.) faz-se necessário alguns ajustes no que tange à quantidade e localização dos centros de distrobuição, pois afetarão diretamente a definição das estratégias de reposição (SIKILERO, RODRIGUES e LACERDA, 2008).

Para Goldratt e Goldratt (2008) e Kendall (2007) ao se definir a quantidade de estoque deve-se levar em conta o consumo e o tempo de reposição. Quanto maior este tempo, maiores 
níveis de estoques devem ser mantidos pelo último elo da cadeia, o lojista. Segundo os autores, o tempo de reposição é segmentado, conforme descrito no Quadro 1.

Tanto o consumo quanto o tempo de reposição estão sujeitos a flutuações estatísticas. Desta forma, quanto maior o nível de serviço requerido, maior ênfase deve ser dada à variabilidade, pois um elevado nível de serviço requer disponibilidade de estoque na posição e no tempo correto dentro da cadeia. Sikilero, Rodrigues e Lacerda (2008) e Rahman (2002) argumentam que quanto maior for a variabilidade de vendas ou o tempo de reposição, tanto maiores necessitarão ser os níveis dos estoques. O nível de estoque a ser mantido pode ser calculado pelo máximo consumo esperado dentro do tempo de reposição, multiplicado por um fator de segurança que traduza o nível de variabilidade considerado.

De fato, faz-se necessário entender os fatores que sustentam os lead times que compõem o tempo de reposição. O Quadro 1 exemplifica os pressupostos que sustentam os lead times na cadeia de suprimentos.

\begin{tabular}{|l|l|l|}
\hline \multicolumn{2}{|c|}{ Lead time } & \multicolumn{2}{c|}{ Pressupostos na Cadeia de Suprimentos } \\
\hline \multirow{2}{*}{ Pedido } & $\begin{array}{l}\text { Tempo que leva para a } \\
\text { colocação do pedido } \\
\text { dentro da cadeia, ou } \\
\text { seja, da venda do } \\
\text { primeiro item até a } \\
\text { encomenda novamente }\end{array}$ & $\begin{array}{l}\text { Para ganhar desconto ou economizar nos custos de frete } \\
\text { há a necessidade de aumentar o tamanho dos lotes, } \\
\text { agrupando os pedidos no ponto de venda. O tempo } \\
\text { transcorrido para que se consiga um agrupamento } \\
\text { satisfatório aumenta o lead time do pedido, pois retarda } \\
\text { sua emissão. }\end{array}$ \\
\hline Processo & $\begin{array}{l}\text { Tempo de fabricação do } \\
\text { produto }\end{array}$ & $\begin{array}{l}\text { Para melhorar a eficiência da operação se utiliza lotes } \\
\text { maiores (redução set up) para produzir o item. Desta } \\
\text { forma, pedidos são acomodados até que essas } \\
\text { quantidades possam ser produzidas, gerando o aumento } \\
\text { Transporte }\end{array}$ \\
$\begin{array}{l}\text { tempo franscorrido para } \\
\text { levar o produto até o } \\
\text { ponto de consumo }\end{array}$ & $\begin{array}{l}\text { Para reduzir o custo de transporte, os pedidos são } \\
\text { reunidos até que atinjam uma quantidade onde o custo de } \\
\text { transporte seja o menor possível }\end{array}$ \\
\hline
\end{tabular}

Fonte: adaptado pelos autores de Goldratt e Goldratt (2008) e Souza, Chiminazzo e Pires (2005).

Quadro 1 - Definições e pressupostos dos lead times na cadeia de suprimentos.

Para Schragenheim (2007), os princípios propostos pela TOC orientam a encontrar formas de reduzir os tempos dos diferentes lead times. Para o lead time de pedido, deve-se, se possível, reduzir a zero, ou seja, tentar repor diariamente em cada ponto de consumo aquilo que foi consumido no dia (Figura 2).

Segundo Schragenheim (2007), para o lead time do processo, deve-se utilizar a metodologia do Tambor-Pulmão-Corda, da TOC, para gerenciamento da produção no chão de fábrica. Por fim, em relação ao lead time de transporte, é preciso encontrar alternativas que possam reduzir o tempo de entrega, tais como: mudança de modal, periodicidade de entregas 
etc. Esse autor sugere, ainda, que seja dada atenção a dois fatores relevantes. Primeiramente, deve-se manter os estoques nos pontos de divergência, ou seja, onde os estoques possam ser utilizados para servir muitos destinos diferentes. O segundo fator diz respeito à utilização de mecanismos para puxar a reposição dos fornecedores e/ou distribuidores a partir do destino.

Assim, para que se tenha o produto disponível em diferentes localidades, faz-se necessário agregar os estoques na fonte, criando armazéns na fábrica ou centros de distribuição. Dessa forma, cada vez que um ponto de consumo vender um produto, este será reposto o mais rápido possível através dos armazéns ou centros de distribuição (SIKILERO, RODRIGUES e LACERDA, 2008).

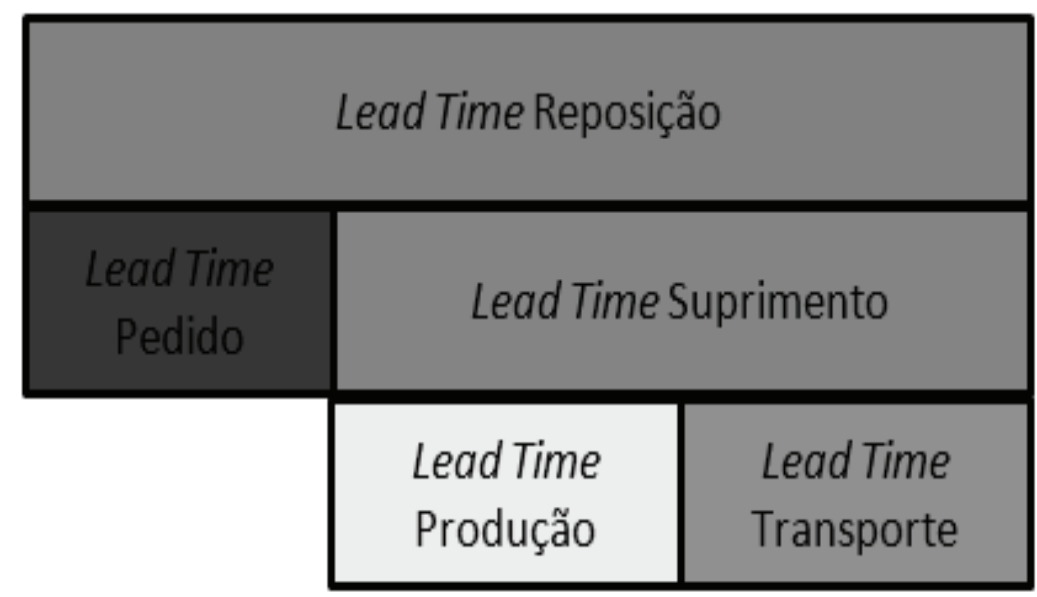

Fonte: os autores (2009).

Figura 2 - Desmembramento dos lead times.

Um trade off que se forma e precisa ser resolvido é o da escolha entre o custo adicional de transporte pelo aumento da frequência de entrega e o custo de se ter menor disponibilidade. Schragenheim (2007) reforça que o aumento na frequência de entrega cria uma melhor disponibilidade, enquanto o custo das remessas aumenta. Reduzindo a frequência, deve-se pagar ou com a disponibilidade menor ou com níveis de estoque maiores nos pontos-devenda. Na maioria dos casos, o custo adicional de transporte é inferior comparativamente à receita adicional produzida. Assim, fica evidente o direcionamento da Teoria das Restrições ao "mundo dos ganhos", uma vez que os Ganhos são a principal medida de orientação dentro da Teoria das Restrições (WATSON, BLACKSTONE e GARDINER, 2007; SIKILERO, RODRIGUES e LACERDA, 2008).

\section{Abordagem metodológica e procedimentos técnicos}

Para Gil (1999), a pesquisa que trata de conhecimentos que buscam resolver lacunas teórico-práticas pode ser classificada como de natureza aplicada. Este trabalho se vincula, por suas peculiaridades, à natureza aplicada descrita pelo autor. A abordagem adotada foi qualitativa, pois a amostra utilizada não possibilita uma generalização em termos de população. Além disso, a necessidade de aprofundamento do entendimento da realidade requer o uso de uma abordagem qualitativa (BRYMAN, 1988).

Em termos de objetivos, essa pesquisa se caracteriza por um foco exploratório (GIL, 1999). Tal característica deriva da tentativa de verificar, em profundidade, as repercussões 
da mudança das políticas de distribuição em uma organização específica. Em termos de procedimentos técnicos, utilizou-se a o Estudo de Caso.

O Estudo de Caso é um método de investigação que se caracteriza pela análise aprofundada de uma determinada realidade. Em relação aos estudos de caso, representam a estratégia preferida quando se colocam questões do tipo "como" e "por que", quando o pesquisador tem pouco controle sobre os eventos e quando o foco se encontra em fenômenos contemporâneos inseridos em algum contexto da vida real. (YIN, 2004; AMARATUNGA et al., 2002).

Segundo Dubé e Paré (2003), os Estudos de Caso são apropriados quando o objeto de investigação é complexo e quando o fenômeno estudado não pode ser analisado fora do contexto onde ocorre. Esse método de investigação também é apropriado nos casos em que é necessária profundidade na pesquisa (DUBÉ e PARÉ, 2003; EINSENHARDT, 1989). As possibilidades de utilização do estudo de caso vão para além do descrito anteriormente. Em seu artigo, Einsenhardt (1989) argumenta e apresenta as possibilidades do Estudo de Caso para a construção de teorias.

Além disso, para Ellram (1996), o Estudo de Caso pode ser utilizado para: (a) explorar um determinado assunto ou problema, entendendo-o profundamente; (b) explanar sobre um fenômeno; (c) descrever um fenômeno; e (d) predizer características de um determinado fenômeno. Alguns dos propósitos para o uso do Estudo de Caso, descritos por Ellram (1996), justificam a utilização desse método para esta pesquisa. A seguir, são detalhados os procedimentos técnicos adotados para a pesquisa.

A Figura 3 apresenta uma visão geral dos procedimentos técnicos adotados para a execução da pesquisa. Inicialmente foi realizada uma revisão do referencial teórico, fundamentado centralmente sobre a abordagem da Teoria das Restrições sobre cadeias de distribuição. Isso decorreu da circunstância de os pesquisadores conhecerem a organização específica e terem o conhecimento de que tais técnicas foram empregadas na organização que foi objeto do estudo.

A seguir, procurou-se compreender o mercado nacional no qual a empresa opera. Esse entendimento teve por objetivo compreender as diferenças existentes nessa organização específica e as demais do setor. Após isso, foi elaborado um instrumento semi-estruturado para a compreensão da realidade específica. Paralelamente a isso, foram identificadas pessoas que poderiam fornecer informações sobre as repercussões da alteração das políticas para alinhamento às propostas da Teoria das Restrições. Após isso, foram realizadas as entrevistas e observações in loco. Por fim, os dados foram analisados e os resultados foram identificados. Na sequência, as principais conclusões foram inferidas. 


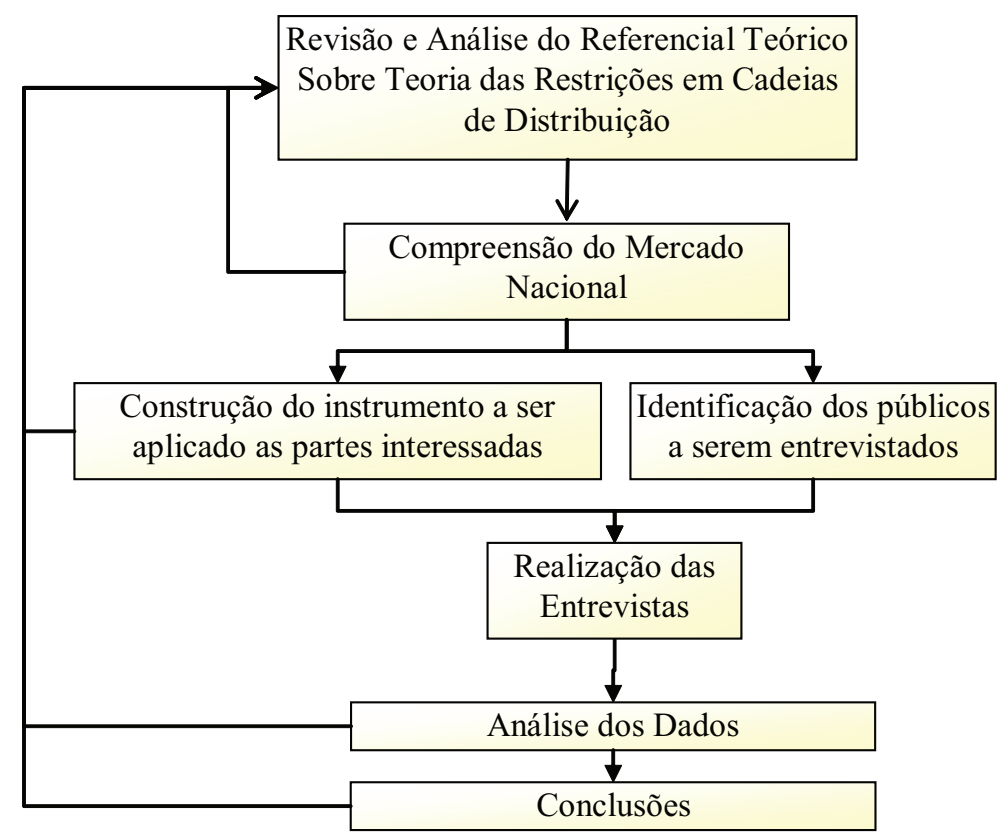

Fonte: os autores (2009).

Figura 3 - Método de trabalho.

A seguir é apresentada uma visão geral sobre o mercado nacional de couros aftermarket. Em seguida, a proposta e seus resultados são apresentados.

\section{$4 \mathrm{O}$ mercado nacional de couros aftermarket}

Em razão da redução nos preços dos artigos em couro e por sua durabilidade, existe uma inclinação para o aumento do consumo de couro para o estofamento de automóveis. Os automóveis que utilizam o estofamento em couro possuem um valor agregado maior em relação ao uso de tecido.

O segmento de mercado denominado de aftermarket é responsável pelo consumo de couros automotivos, que não necessitam atender as especificações técnicas e de processo das montadoras, entre elas, a certificação na Norma ISO/TS 16.949:2002, responsável pelo Sistema de Garantia da Qualidade para fornecimento de peças OEM (original equipment manufacture), que compõem os automóveis saídos de fábrica, ou seja, peças originais. Este fato propicia a existência de um número maior de fornecedores. Dessa forma, o mercado de couros aftermarket é definido por aqueles revestimentos colocados pelo proprietário em empresas especializadas, que não as montadoras.

Analisando-se este mercado, segundo as forças competitivas de Porter (1986), as que exercem maior influência estão relacionadas à ameaça de novos entrantes e ao poder de negociação dos compradores. Por tratar-se de distribuição rodoviária, o delivery time gira em torno de cinco dias. O lead time produtivo do couro, para estofamento automotivo, é de aproximadamente oito dias a partir da matéria-prima wet blue, e o lead time de transporte até São Paulo, maior centro consumidor, é de aproximadamente dois dias, a partir de Porto Alegre.

Essa diferença de tempo implica na colocação de pedidos urgentes na fábrica para atender o prazo solicitado e contratado com o cliente. A entrada destes pedidos com status de urgência causam reprogramações na fábrica para sua alocação. A repetição deste procedimento de alocação gera, com o passar do tempo, uma redução na confiabilidade de entrega dos 
pedidos dentro do prazo contratado. Isso decorre do fato de que os pedidos urgentes, por vezes, não são entregues e sua alocação afeta a entrega dos pedidos já contratados que necessitam adiamento.

O atraso nas entregas aumenta a insegurança por parte dos clientes em relação ao cumprimento dos prazos futuros por parte do fornecedor. Esta insegurança gera mecanismos de proteção, por parte do cliente, para garantir sua produção/comercialização. Esta proteção, normalmente, tem caráter preventivo através da redução do delivery time, deixando uma margem de tempo de segurança, contando com o atraso por parte do fornecedor, alimentando, dessa forma, um círculo vicioso de reforço que alimenta a existência de atrasos nas entregas, conforme ilustrado na Figura 4.

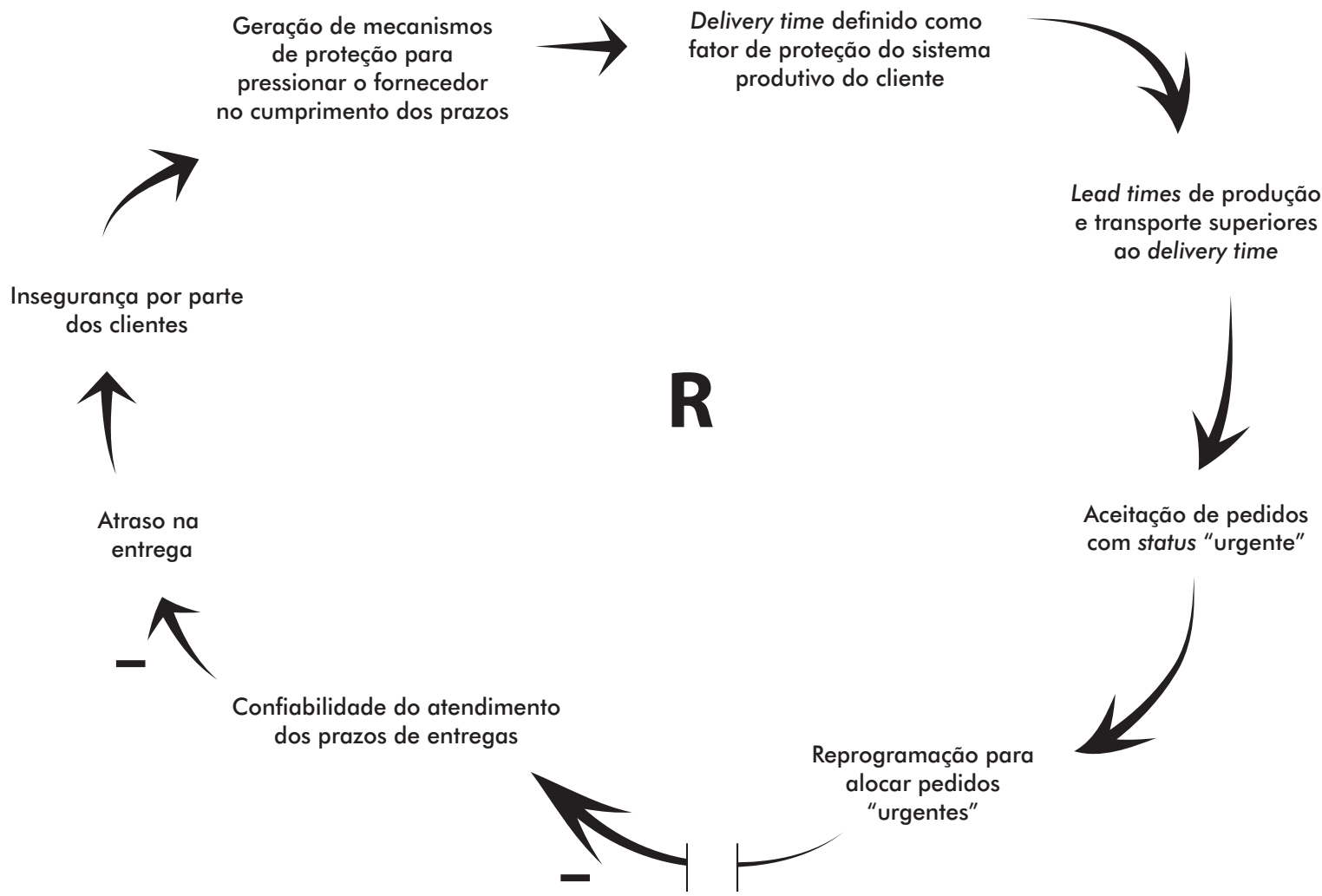

Fonte: elaborada pelos autores.

Figura 4 - Enlace reforçador gerado entre as diferenças no delivery time e os lead times de produção e transporte.

Uma leitura da Figura 4 pode ser feita da seguinte maneira: quanto maior a proteção do cliente através da definição de um delivery time curto, maior será a diferença deste com relação aos lead times de transporte e produção. Quanto maior esta diferença, maior é a aceitação de pedidos com status de urgente que entram na produção. Quanto maior a entrada de pedidos com status de urgente, maior é a necessidade de reprogramação para alocar estes pedidos urgentes. Com o passar de certo tempo, menor será a confiabilidade do sistema produtivo para o cumprimento dos prazos dos pedidos normais e urgentes. Quanto menor a confiabilidade, maior os atrasos nas entregas. Quanto maior os atrasos, maior a insegurança por parte dos clientes. Quanto maior esta insegurança, maior será a geração de mecanismos de proteção para pressionar o fornecedor a cumprir os prazos. Quanto maior for a geração destes mecanismos, 
mais o delivery time será usado para pressionar a entrega, gerando um espiral que Andrade et al. (2006) denominam de enlace reforçador.

O mercado de couros aftermarket apresenta as seguintes características:

- mix de produto simplificado com poucas variações de cores e estampas;

- pedidos em pequenas quantidades, com grandes frequências de entrega;

- lead time de transporte baixo;

- delivery time baixo, em comparação a pedidos de exportação;

- padrões de qualidade variados, indo desde inferior a semelhante ao praticado pelas montadoras e para o mercado de exportação.

Dentro desse cenário, procurou-se traçar ações genéricas para o melhor posicionamento dos estoques dentro da cadeia. Por definição, a cadeia engloba quatro tipos de organizações, conforme apresentado no Quadro 2.

\begin{tabular}{|l|l|}
\hline \multicolumn{2}{|c|}{ Organização } \\
\hline $\begin{array}{l}\text { Empresa fabricante do couro } \\
\text { (fornecedor) }\end{array}$ & $\begin{array}{l}\text { Processos que ocorrem em grandes áreas: } \\
\text { matéria-prima, semi-acabado e acabamento; }\end{array}$ \\
\hline Transportadora (distribuidor) & Operação de conduzir do fornecedor até o cliente \\
\hline $\begin{array}{l}\text { Empresa manufatureira do couro } \\
\text { (cliente) }\end{array}$ & $\begin{array}{l}\text { Processos que ocorrem em quatro grandes áreas: } \\
\text { modelar, corte, costura e montagem }\end{array}$ \\
\hline Proprietário do veículo (consumidor): & Usuários finais. \\
\hline
\end{tabular}

Fonte: elaborado pelos autores.

Quadro 2 - Organizações da cadeia de suprimentos.

\section{Situação atual para o atendimento do mercado nacional}

Normalmente, os fornecedores mantêm um estoque de matérias-primas ou, no máximo, de couros no estágio semiacabado, objetivando a agilidade e redução no tempo de entrega. O que os fornecedores, por vezes, ignoram é que o estoque de couros no estágio semiacabado não resolve e nem ameniza o problema de baixa confiabilidade de entrega que existe atualmente, pois enquanto há a redução do lead time até semiacabado, há o aumento da frequência de setups no acabamento (Figura 5).

Para a montagem da proposta deste artigo, alguns pressupostos precisam ver analisados. Inicialmente a produção caracteriza-se por make-to-order; dessa forma, um pedido que não possua status de urgente leva, no mínimo, oito dias para ficar pronto. Sendo assim, a estratégia de deixar o estoque em matéria-prima não contribui para possuir o couro na hora certa.

Uma produção make-to-stock, levando os couros até o estágio de semiacabado, objetiva reduzir o lead time de produção, devido ao tempo de entrega do couro a partir do semiacabado ser de três dias, contra os oito dias a partir da matéria-prima. Neste ponto, há um trade-off, pois o setup dos processos de pinturas demandam um tempo significativo, cerca de 30 a 60 minutos por lote (abastecer o sistema de pulverização, aplicar, verificar cor, liberar/corrigir, desabastecer o sistema de pulverização, lavar sistema de pulverização etc.). Isso implica em consumir a disponibilidade da máquina para a produção, pois as entregas são, normalmente, em pequenos lotes semanais para cada cliente. Esta combinação de pequenos lotes (aumento 
da frequência) com longos tempos de setup reduz a capacidade produtiva, aumentando o lead time do processo de acabamento.

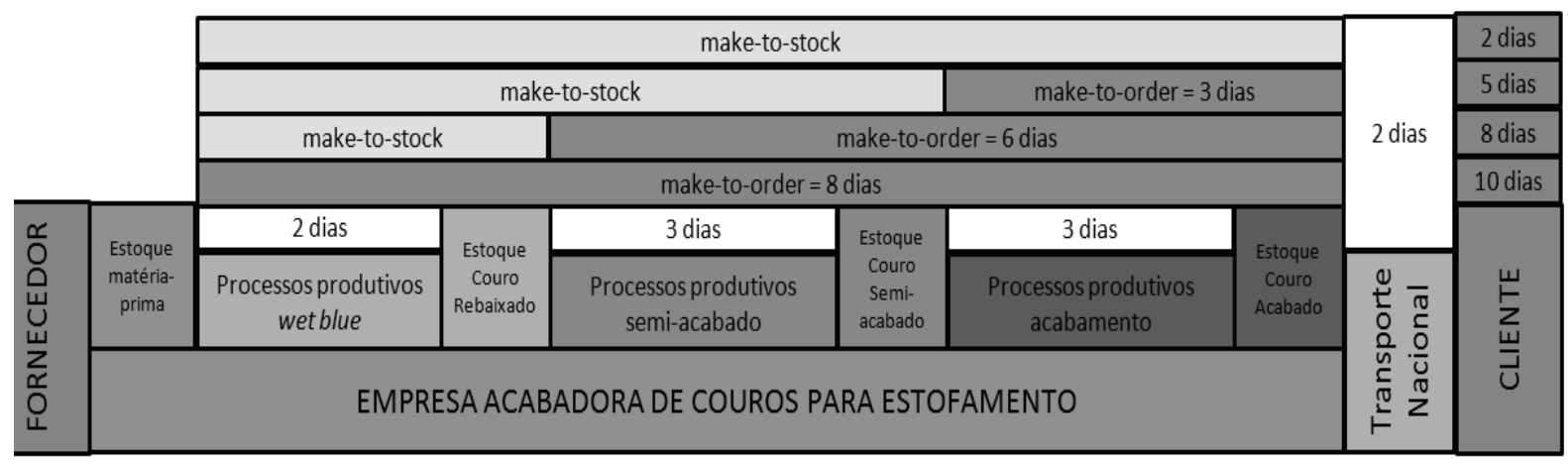

Fonte: elaborada pelos autores.

Figura 5 - Relação dos leads times e as estratégias de fornecimento.

Outro aspecto a ser considerado é o aumento do consumo de produtos químicos em função do desperdício. A cada desabastecimento da máquina de pintura para a troca de cor, pode-se perder, conforme o modelo do maquinário, aproximadamente $10 \mathrm{~kg}$ de tinta, que ficam dentro do sistema de pulverização e/ou saem com a água da lavagem do sistema. Há maior variação de tonalidades de cor entre os lotes, porque, quando se faz pequenos lotes da mesma cor, várias vezes ao mês, ao agrupar todas as entregas, pode-se verificar uma grande variação de cor entre os lotes entregues, ou seja, na amplitude.

\section{Solução proposta fundamentada nas orientações da Teoria das Restrições para Distribuição} na sequência:

Para a maximização do ganho, foi realizada a seguinte heurística, que será discutida

1. Mapear as cores produzidas em um determinado espaço de tempo confiável (mês, trimestre, semestre, ano etc.);

2. Identificar quais as cores com maior índice de repetitibilidade;

3. Traçar estratégias de produção derivada do resultado das análises anteriores, conforme sugestões apresentadas a seguir:

- para cores com alta repetitibilidade (standard): fazer make-to-stock, deixando o couro pronto no estágio semiacabado e acabado, criando um buffer em semi e outro em acabado,

- para cores com baixa repetitibilidade (special): fazer make-to-order, avaliando a disponibilidade de couros no estágio semi-acabado que possam ser aproveitados. aspectos:

4. Um detalhamento maior de cada estratégia deve abranger, pelo mínimo, os seguintes

- os tempos de setup do semiacabado são significativamente inferiores ao do acabamento, pois no semiacabado não há preparação de cores,

- uso da tecnologia de grupo para unificar a maior quantidade possível de pequenos lotes em determinados processos semelhantes, ganhando em escala (cor do semiacabado, gravação etc.).

A estratégia para cores standard consiste em manter um estoque de produtos acabados, reduzindo o lead time de produção para zero, havendo somente o lead time de transporte. 
Com o estoque no estágio acabado, os pedidos de cores standard podem ser feitos diariamente, sem necessidade de aguardar o somatório do consumo de um grande período para formar o lote de pedido. Como há couros em estoque, todos os dias podem ser expedidos couros do fornecedor para os clientes, através de transportadora contratada, sem custo adicional em função do lote menor.

Ainda nas cores standard, devido à cor do semiacabado ser a mesma para uma grande gama de cores acabadas, pode-se ter um estoque em semiacabado destas cores, o que possibilita uma interação entre o volume expedido no acabamento e a formação de lotes econômicos para reduzir os setups do acabamento. Esta proposta é de fácil implementação, pois basta monitorar o consumo do estoque acabado. Quando o estoque de couros acabados na expedição atingir o ponto de pedido programado (consumo + lead time de produção do semi ao acabado), autoriza-se o acabamento de um lote econômico para a reposição do estoque.

Quando o estoque de couros semiacabado chega ao ponto de pedido programado (consumo + lead time de produção da matéria-prima ao semiacabado), emite-se uma ordem de produção para o setor de matéria-prima, que monta um novo lote para o semiacabado. Como as cores do semiacabado são poucas, pode-se utilizar a mesma sistemática de abastecimento da expedição de couros acabados.

A estratégia para cores special é de uma produção normal make-to-order, ou seja, produzir somente quando houver pedido, pois o risco de se manter estas cores em estoque e as mesmas ficarem obsoletas é muito alto. Existe também a possibilidade de buscar no estoque de semiacabado cores de fundo que possam ser utilizadas nos pedidos para acabamento, eliminando a necessidade de montagem de lote na matéria-prima. Dessa forma, pode-se consumir couros do estoque semiacabado, que é standard, com couros de cor de acabamento special, gerando aproveitamento da matéria-prima.

\section{Considerações finais}

Com a adoção dessas estratégias, o nível de atendimento tende aumentar significativamente sem a necessidade de investimento em infraestrutura, pois se cria um desacoplador entre delivery time e o lead time de produção e pedido. A expedição de pedidos standard prontos é transformado somente no tempo do lead time de transporte, que gira no máximo em dois dias, contra os 10 anteriores (lead times produção, transporte). O fornecedor pode valer-se deste avanço, para garantir o prazo de entrega de cinco dias, o que é inferior ao praticado pelo mercado, cobrando uma pequena diferença para pedidos com status "urgente", entregas em dois dias, sem necessitar reprogramar a fábrica e sem esforço, pois os couros já estariam prontos na expedição, o que garantiria produtos na hora certa.

A possibilidade de produzir lotes econômicos no semiacabado e no acabado pode propiciar que pedidos standard possam ser embarcados em menor quantidade e maior frequência. Isso não implica em prejuízo para a empresa, garantindo a quantidade certa.

A redução de setup nas operações de acabamento, em função da produção de lotes econômicos, reduz drasticamente as variações entre lotes de mesma cor, o que era gerado quando da produção de pequenos lotes repetidamente da mesma cor. Essas ações garantem a qualidade certa requerida.

As cores special serão comercializadas normalmente dentro do prazo de mercado, com a diferença que a maioria das entregas (standard) é feita com prazo inferior ao mercado; dessa forma, reduzirá a quantidade de pedidos com status urgente, rompendo o círculo vicioso e criando um círculo virtuoso com enlace balanceador. 


\section{Limitações e recomendações para estudos futuros}

São diversas e distintas as limitações que circundam desse estudo. Por um lado, essas limitações circunscrevem o nível de contribuição do presente trabalho. Por outro lado, abrem o caminho para uma discussão mais profunda e para a realização de outros trabalhos acadêmicos.

Nesse sentido, inicialmente, um aspecto que deve ser considerado diz respeito à generalização desse estudo de caso em termos populacionais. Por tratar-se de um estudo de caso único, apropriado para o tipo de investigação executada onde se procurava certa profundidade, as possíveis generalizações em termos populacionais torna-se comprometida.

Tal aspecto não invalida as conclusões do ponto de vista teórico, mas encaminha a necessidade de realização de levantamentos quantitativos mais amplos que permitam um maior grau de generalização dos resultados. Outra possibilidade seria a replicação do estudo em outras organizações desse mesmo segmento para que a verificação dos resultados encontrados, uma vez adotada abordagem semelhante, obtenha maior robustez.

Uma limitação desse estudo que, ao mesmo tempo fornece sua relevância, é a falta de estudos que apliquem a Teoria das Restrições para o gerenciamento da Cadeia de Suprimentos. Nesse sentido, o trabalho esteve limitado aos artigos, nacionais e internacionais, que versaram sobre o tema. Igualmente tal aspecto proporciona originalidade do trabalho sob o ponto de vista da aplicação da Teoria das Restrições em si, mas também na aplicação no setor de coureiro que possui um papel importante na economia do estado, em particular, e do país, em geral.

Dessa forma, uma sugestão é a realização de outros trabalhos que utilizem a Teoria das Restrições para compreensão da realidade e para o fornecimento de soluções gerenciais que possam incrementar a competitividade das organizações. Outra possível contribuição que futuros estudos podem proporcionar é a utilização da lógica empregada neste estudo para outros setores e, por consequência, a checagem dos resultados encontrados e, principalmente, dos fatores determinantes para os mesmos.

Outra limitação do trabalho que pode encaminhar outros trabalhos nessa linha é a utilização de ferramentas de simulação computacional. Essas ferramentas poderiam auxiliar na simulação da realidade específica e contribuir para melhorias nas heurísticas sugeridas para além das propostas pela Teoria das Restrições. Além disso, os resultados quantitativos, decorrentes dessas ferramentas e validados estatisticamente, poderiam fornecer maior robustez aos resultados obtidos.

O nível de abertura dos dados foi um aspecto limitante desta pesquisa. Infelizmente foram acessados os dados disponibilizados que, basicamente, se restringiram ao tempo de atendimento. Tal fato decorre de fatores que iniciam com alta competitividade no setor e perpassam a própria estruturação dos dados. Para os fins deste trabalho, o aspecto do tempo de atendimento foi suficiente para fornecer os indícios necessários dos impactos da aplicação da Teoria das Restrições. Contudo, pesquisas que possam comparar informações referentes a custos ou que tenham séries históricas amplamente estruturadas podem, sobremaneira, contribuir para a uma maior validade interna dos resultados apresentados.

Enfim, os aspectos destacados anteriormente conferem o caráter transitório de qualquer contribuição científica. Tal contribuição se configura transitória, pois encaminha e abre a discussão para novas contribuições em termos de teoria, de aplicação e da própria análise crítica dos dados. 


\section{Referências}

AMARATUNGA, Dilanthi; BALDRY, David; SARSHAR, Marjan; NEWTON, Rita. Quatitative and qualitative research in the built environment: application of "mixed" research approach. Work Study, Emerald, v. 51, n. 1, p. 17-31, 2002.

ANDRADE, Aurelio; SELENE, Acyr; RODRIGUES, Luís Henrique; SOUTO, Rodrigo. Pensamento sistêmico: caderno de campo - o desafio da mudança sustentada nas organizações e na sociedade. Porto Alegre: Bookman, 2006.

BRYMAN, Alan. Quantity and quality in social research. London: Unwin Hyman, 1988.

DUBÉ, Line; PARÉ, Guy. Rigor in information systems positivist case research: current practices, trends and recommendations. MIS Quaterly, v.27, n.4, p.597-635, 2003.

EINSENHARDT, Kathleen M. Building theories from case study research. Academy of

Management Review, Stanford, v.14, p.532-550, 1989.

ELLRAM, Lisa M. The use of the case study method in logistics research. Journal of Business Logistics, Arizona, v.17, n.2, p.93-138, 1996.

GIL, Antonio Carlos. Métodos e técnicas de pesquisa social. São Paulo: Atlas, 1999.

GOLDRATT, Eliyahu M. A síndrome do palheiro: garimpando informações num oceano de dados. 2. ed. São Paulo: Educator, 1991.

GOLDRATT, Eliyahu M. A meta. 2. ed. São Paulo: Educator, 1993.

GOLDRATT, Eliyahu M.; GOLDRATT, Avraham. Tópicos em distribuição. Goldratt Marketing Goup. 2008. Disponível em < https://www. toc-goldratt.com/category/TOC-Insights $>$. Acesso em: 12 jul.2008.

GUPTA, Mahesh C.; BOYD, Lynn H. Theory of constraints: a theory of operations management. International Journal of Operations and
Production Management, v.28, n. 10, p.9911012, 2008.

KENDALL, Gerald I. Visão viável: transformando o faturamento em lucro líquido. Porto Alegre: Bookman, 2007.

MENEZES, Felipe Morais; DA LUZ, Gilberto Barbosa. Avaliação da solução logística da teoria das restrições através de Simulação Computacional. In: ENCONTRO NACIONAL DE ENGENHARIA DE PRODUÇÃO (ENEGEP), 26., 2007, Foz do Iguaçu. Anais eletrônicos... Foz do Iguaçu: ENEGEP, 2007. Disponível em < http:// www.abepro.org.br/biblioteca/ENEGEP2007_ TR570433_9759.pdf>. Acesso em: 02 out. 2009.

PORTER, Michael E. Estratégia competitiva: técnicas para análise de indústrias e da concorrência. 16. ed. São Paulo: Campus, 1986. RAHMAN, Shams-Ur. Theory of constraints thinking process approach to developing strategies in supply chains. International Journal of Physical Distribution and Logistics Management, v. 32, n. 10, p.809-828, 2002.

SCHRAGENHEIM, Amir. Gerenciando a distribuição de acordo com os princípios da TOC. Heptagon, 2007. Disponível em: < Http:// www.heptagon.com.br>. Acesso em: 06 jan. 2009.

SIKILERO, Cláudio Bastos; RODRIGUES, Luis Henrique; LACERDA, Daniel Pacheco. Análise crítica das soluções da teoria das restrições para o gerenciamento da cadeia de suprimentos: uma análise teórica. In: ENCONTRO NACIONAL DE ENGENHARIA DE PRODUÇÃO (ENEGEP), 28. 2008, Rio de Janeiro. Anais eletrônicos... Rio de Janeiro: ENEGEP, 2008. Disponível em: <http://www.abepro.org.br/biblioteca/ enegep2008_TN_STO_069_490_11116.pdf $>$. Acesso em: 02 out. 2009.

SOUZA, Fernando Bernardi; CHIMINAZZO, Marcos; PIRES, Silvio R. Inácio. Um estudo teórico sobre a aplicação da teoria das restrições na gestão da cadeia de suprimentos. In: SIMPÓSIO DE ENGENHARIA DE PRODUÇÃO (SIMPEP), 12. 2005 Bauru. Anais eletrônicos... 
Bauru: SIMPEP, 2005. Disponível em: < http:// www.simpep.feb.unesp.br/anais_simpep_aux. php?e=12>. Acesso em: 02 out. 2009.

YIN, Robert K. Estudo de caso: planejamento e métodos. 2. ed. Porto Alegre: Bookman, 2004.

WATSON, Kevin J.; BLACKSTONE, John H.; GARDINER, Stanley. The evolution of a management philosophy: the theory of constraints. Journal of Operations

Management, v. 25, n. 3, p.387-402, 2007. 